\title{
An Exploration of Public Events and Alcohol Related Incidents
}

\author{
Briana A. Holliday* \\ Undergraduate, University of Illinois at Urbana-Champagin, Kankakee, IL, USA
}

\section{Objective}

The objective for this research project was to see if there are predictable patterns for certain annual events in Champaign County, Illinois. The focus was on how alcohol intoxication effected the population and whether or not its effects were dangerous to the community at an alarming rate.

\section{Introduction}

Champaign County is one of the largest counties in central Illinois with a population of $\sim 207,000$ and is home to the University of Illinois at Urbana-Champaign which currently has 44,500 students. In the fall the university hosts Big Ten football games which have recently been drawing an average attendance of $\sim 45,000$ people, many traveling from Chicago or other parts of the Midwest ${ }^{1}$. The twin cities host a number of community events and festivals throughout the Spring and Summer. Typically the community festivals have liquor licenses whereas no alcohol is served in the football stadium. Despite the lack of alcohol availability in the stadium many fans drink during tailgate parties before and after the game.

\section{Methods}

In order to assess the impact of alcohol at Champaign-Urbana mass gatherings we extracted records of patients seeking alcoholintoxication related treatment at Carle Foundation Hospital from INDICATOR $^{2}$ between 2011 and 2014. We also obtained police citation data for driving under the influence (DUI) and minor in possession (MIP) from the Urbana, Champaign, and University of Illinois Police Departments over the same period. The number of patient visits and citations for home football games were compared using an unmatched t-test to Fall weekends without a home game. The number of patient visits and citations for the Illinois Marathon, Taste of Champaign, Boneyard Creek Arts Festival, Urbana Sweetcorn Festival, and Rhythm and Brews Music Festival were compared against the event-less 2 weekends before and after the event.

\section{Results}

Over the 4 year period of the study there were 29 Fall Saturdays with a home football game and 24 without. Of these the difference in the number of minor in possession citations were highly significant (mean $=20.72$ v 5.04, $\mathrm{p}<0.0001$ ) whereas there was no statistical difference in number of DUI citations (mean $=1.21 \mathrm{v} 1.25, \mathrm{p}>.1$ ) or hospital emergency department visits (mean $=5.24 \mathrm{v} 4.33, \mathrm{p}>0.1$ ).

Over the same 4 year period there were 25 Spring weekend days with City Festivals and 47 weekend days without them. Of these the difference in the number of minor in possession citations were significant (mean $=8.68 \mathrm{v} 4.27, \mathrm{p}<0.05$ ) as were the number of DUI citations (mean $=1.44$ v $0.91, \mathrm{p}<.05)$. Hospital emergency department visits were not significantly different (mean $=3.4$ v 3.23, $\mathrm{p}>0.1$ ).

During the summer months when the population of ChampaignUrbana is significantly reduced by the absence of students there were 57 days with city festivals and 123 days without them. Again the difference in MIP cases was significant (mean $=3.72 \mathrm{v} 1.53$, $\mathrm{p}<0.0001$ ), whereas there was no statistical difference in number of DUI citations (mean $=0.631 \vee 0.642, p>.1)$ or hospital emergency department visits (mean $=2.68$ v 2.93, $\mathrm{p}>0.1$ ).

\section{Conclusions}

The results from this research have started looking at how alcohol effects the Champaign County community. While minor in possession counts are significantly increased during home football games there does not seemed to be immediate danger to the community, considering driving under the influence and reported acute alcohol intoxication hospital visits were not significantly above background. It is interesting however that on preliminary analysis there is a significant increase in the number of DUI citations during Spring Festivals. Further work will seek to confirm the validity of these observations and develop predictive models of the number of alcohol related cases taking into account additional factors such as weather, attendance, and the team's record.

Home Football Games

\begin{tabular}{|c|c|c|c|c|c|}
\hline & Home Football Games & Home Football Game & No Home Games & No Home Game & P-Value \\
\hline & Mean $(\mathrm{n}=29)$ & Standard Deviation & Mean $(\mathrm{n}=24)$ & Standard Deviation & \\
\hline MIP & 20.72 & 11.0033 & 5.041 & 4.0979 & $<0.0001$ \\
\hline DUI & 1.21 & 1.0770 & 1.2500 & 1.0260 & .8912 \\
\hline Carle ED & 5.24 & 3.3493 & 4.33 & 3.6818 & .351 \\
\hline
\end{tabular}

\section{Keywords}

alcohol; mass gatherings; college; street festivals

\section{Acknowledgments}

We would like to thank Carle Foundation, Urbana Police Department, Champaign Police Department, and University of Illinois Police Department for sharing data and a special thanks to I3 for funding this project.

\section{References}

1. 2015 Fighting Illini Record Book

2. W. Edwards, A. Vaid, and I. Brooks, "INDICATOR: An Opensource Cyberenvironment for Biosurveillance," in Defining Crisis Management 3.0

*Briana A. Holliday

E-mail: hollida2@illinois.edu 